Article

\title{
Electric Bicycle Lane-Changing Behavior under Strategy Games
}

\author{
Haipeng Shao ${ }^{1, *(\mathbb{D})}$, Jiangping Wang ${ }^{1}$, Yin Wang ${ }^{2}$ and Sitian Chen ${ }^{1}$ \\ 1 School of Highway, Chang'an University, Xi'an 710064, China; wangjp@chd.edu.cn (J.W.); \\ chenst@chd.edu.cn (S.C.) \\ 2 Baker Tilly China Certified Public Accountants (Xinjiang Branch), Urumqi 830000, China; \\ iso7029@dingtalk.com \\ * Correspondence: shaohp@chd.edu.cn; Tel.: +86-138-9187-6221
}

Received: 31 July 2018; Accepted: 22 August 2018; Published: 24 August 2018

\begin{abstract}
The random lane-changing behavior of electric bicycles brings a great safety hazard to urban transportation: According to the national traffic accident statistics in 2015, 8.22\% of traffic accidents are caused by non-motor vehicle violations. Among them, the accident rate caused by electric bicycles is as high as $78 \%$. In order to effectively analyze and quantify the risk of this lane-changing behavior, based on the non-cooperative strategy model under complete information, a Z-test of the speed before and after the "illegal" lane-changing behavior was carried out by using the data of the mixed-flow sections of Xi'an city. Constructing the judgment matrix to determine the weight value of motor vehicles' game strategy and constructing the charge matrix, the utility income analysis of the electric bicycle and the affected motor vehicle is made by using the payment function, and the exceeding conflict model is established to quantify the risk level of the conflict number in the unit road. It is verified that the "illegal" lane-changing behavior of electric bicycles is a goal-oriented behavior for obtaining greater desired speed.
\end{abstract}

Keywords: lane-changing behavior; strategic game model; Z-Test; conflict model; expected speed

\section{Introduction}

As the main body of non-motor vehicles in urban areas, electric bicycles can provide "door to door" travel service for residents, but their "illegal" traffic behavior, such as speeding and driving randomness, bring a great safety hazard. Currently, the traffic in China cities is mixed flow, and in many circumstances, motor vehicles and non-motor vehicles are separated only by the line, with no isolation facilities such as guardrails; especially in some small- and medium-sized cities, the phenomenon of mixing is more obvious. Therefore, it is of great practical significance to improve urban traffic safety management through studying the random lane-changing behavior of electric bicycles from bicycle lanes to motorlanes under mixed-traffic circumstances. In terms of traffic flow characteristics, there are many ways to analyze the impact of electric bicycles on motor vehicle flow as well as the design approaches of electric bicycle facilities under the circumstances of traffic congestion [1-4]. Most applications of Game Theory in this area are for the study of motor vehicle flow, but applications and studies on electric bicycles are very few [5-12].

In order to study the safety behavior of electric bicycles at intersections, Tieqiao Tang uses a Nagel-Schreckenberg model to analyze electric bicycles' crossing and retrograde behavior [13], and Lu Bai uses the conflict prediction model to compare the number of accidents between bicycles and electric bicycles [9]; the safety level of driving behavior of the electric bicycle has been analyzed by several methods, such as accident tree analysis, Likert scale, and traffic conflict technology, and so on [14-17].The difference between the electric bicycle and traditional non-motor vehicle safety leads 
to differences in vehicle ownership [18,19], and has also changed the urban transportation mode. The previous literature includes studies on driving behavior from the above three aspects, but less attention is paid to the "illegal" behavior of the electric bicycle.

Therefore, this paper will explore the "illegal" lane-changing behavior of electric bicycles based on the non-cooperative strategy game model with complete information. Simi motion is used to obtain the data, and the velocities of the electric bicycles from the non-motorized lane into the motorized lane and the motorized lane change into the non-motorized lane are tested, and the benefit of "illegal" driving is analyzed. Using the judgment matrix, the pricing matrix of the strategic game is established, and the optimal solution is analyzed. At the same time, in order to quantify the risk of "illegal" lane changing, through the actual survey in sections, the safety threshold of the dangerous degree of lane-changing behavior is obtained by field survey and data analysis by Origin software.

\section{Method of Exploring Electric Bicycle Lane-Changing Behavior}

\subsection{Strategy Games Method}

In the roads with mixed traffic flow, electric bicycles and motor vehicles usually have game conflict because of competing for road space; when driving, both of them will take a certain strategy to get the right of way. The strategy type, road geometric characteristics, and traffic information will be known to each other, but there is no cooperative relationship because there is a conflict of interest between them. In order to analyze the traffic conflicts between electric bicycles and motor vehicles on mixed-traffic roads, the non-cooperative complete information strategy game is used to describe this phenomenon.

Model assumptions:

(1) The flow of the investigated road section is mixed traffic flow. The road section is $200 \mathrm{~m}$ away from the upstream and downstream intersections with large traffic volume about $1100 \mathrm{pcu} / \mathrm{h}$.

(2) The behavior of electric bicycle change into the motorized lane is free lane-changing behavior.

(3) The game behavior of lane changing is a non-cooperative dynamic game with complete information.

(4) All of the non-motor vehicles studied are electric bicycles.

For a strategy game, assuming $\Gamma$ is a finite game,

$$
\Gamma=\left(N,\left(C_{i}\right)_{i \in N^{\prime}}\left(u_{i}\right)_{i \in N}\right)
$$

where $N$ is player set; $C_{i}$ is strategy set of player $i ; u_{i}: C \rightarrow R$ is the utility payments of players. When each player chooses one strategy from $C_{i}, C$ is the set of profile strategies chosen by all players, $C=\underset{i \in N}{\times} C_{i}$. The necessary and sufficient condition of $\sigma$ being a stochastic strategy profile in $\times_{i \in N} \triangle\left(C_{i}\right)$ is that, for each player $i$ and each pure strategy in $C_{i}, \sigma$ determines a non-negative real number $\sigma_{i}\left(c_{i}\right)$ indicating the probability of player $i$ choosing $c_{i}$ to make $\sum_{d_{i} \in c_{i}} \sigma_{i}\left(d_{i}\right)=1$. For any stochastic strategy combination $\sigma$, when all the players choose their pure strategy according to $\sigma$, the expected utility paid of the player $i$ is $u_{i}(\sigma)$, where

$$
u_{i}(\sigma)=\sum_{c \in C}\left(\prod_{j \in N} \sigma_{j}\left(c_{j}\right)\right) u_{i}(c), \forall_{i} \in N
$$

A strategy set of an electric bicycle is \{changing lane, not changing lane\}, the probability is $\{p, 1-p\}$. The electric bicycles' sudden "invasion" into the motorized lane forces motor vehicles to make corresponding reactions; their reaction strategies include accelerating stop bicycle, decelerating yield, and changing lane. If there is any $i \in N$, any $c_{i}{ }^{*} \in C_{i}$, then strategy profile $\left(c_{1}{ }^{*}, \cdots, c^{*}{ }_{i-1}, c^{*}{ }_{i}, c^{*}{ }_{i+1}, \cdots, c^{*}{ }_{N}\right) \in C_{i}$ is a "Nash equilibrium". 
In mixed traffic flow, the lane changing of electric bicycles into motor vehicle lanes has the greatest impact on the nearest motor vehicle. Therefore, the two-person non-cooperative game is used to describe the lane-changing behavior of electric bicycles. There are two motivational strategies for electric bicycles: change lane or do not change lane. The nearest motor vehicle can choose to slow down to avoid, speed up to refuse to merge, or change lanes to enter another motor vehicle lane for the electric bicycles entering the lane change. In other words, the motor vehicle's coping strategies for the electric bicycles' lane-change behavior include deceleration to avoid, acceleration to stop, and change lanes. The flow chat of the game behavior of electric bicycle is shown in Figure 1.

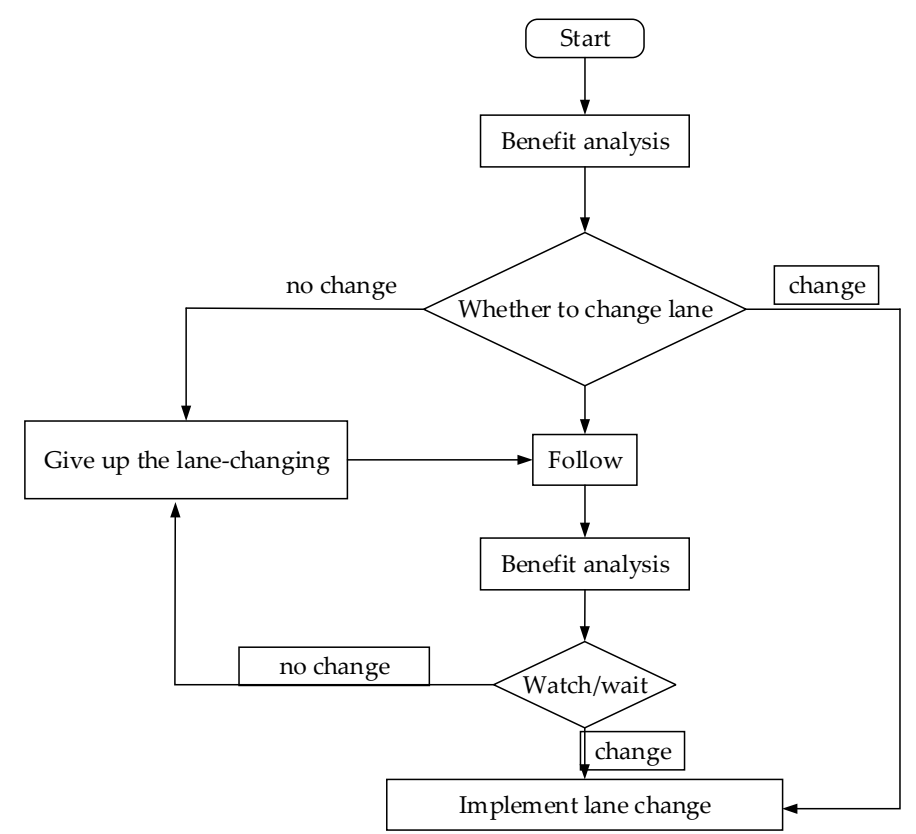

Figure 1. Lane changing flow chart.

\subsection{Data Acquisition}

In order to further analyze the lane-changing behavior of electric bicycles between bicycle lanes and motorized lanes, the mixed traffic flow sections of Zhangbadong road, Yanta interchange, Chang'an interchange, and Nan'erhuan road in Xi'an were investigated, and data were obtained to establish the benefit matrix of the game model.

(1) The correlation coefficient of velocity before and after lane changing is $\eta_{1}=0.88847$. A Z-test of the average difference of the speed of electric bicycles before and after lane changing for the two groups of speed samples indicated that the mean value of the speed before and after the lane- changing is significantly different. In other words, the average speed of the electric bicycles who changed into the motor lane increased. The Z-test result is shown in Table 1.

Table 1. Lane changing Z-Test: Double sample average difference test.

\begin{tabular}{|c|c|c|}
\hline Parameter & Before Lane Changing $(\mathrm{km} / \mathrm{h})$ & After Lane Changing $(\mathrm{km} / \mathrm{h})$ \\
\hline Mean & 12.082 & 12.767 \\
\hline Known Covariance & 1.903 & 2.094 \\
\hline Observation Value & 100 & 100 \\
\hline Hypothetical Mean Difference & \multicolumn{2}{|c|}{0} \\
\hline Z & \multicolumn{2}{|c|}{-3.429} \\
\hline $\mathrm{P}(\mathrm{Z} \leq \mathrm{z})$ Single Tail & \multicolumn{2}{|c|}{0.000302} \\
\hline z Single Tail Critical & \multicolumn{2}{|c|}{1.645} \\
\hline $\mathrm{P}(\mathrm{Z} \leq \mathrm{z})$ Double tail & \multirow{2}{*}{\multicolumn{2}{|c|}{$\begin{array}{c}0.000605 \\
1960\end{array}$}} \\
\hline z Double Tail Critical & & \\
\hline
\end{tabular}


(2) The correlation coefficient of the speed of before and after the electric bicycles transfer from the motorized lane to the bicycle lane is $\eta_{2}=0.90171$.

A Z-test of the average difference of the speed of electric bicycles before and after lane changing for the two groups of speed samples indicated that the mean value of the speed before and after lane changing is significantly different. In other words, the electric bicycle obtains higher speed through changing from the bicycle lane to the motored lane and then back to the bicycle lane. The Z-test result is shown in Table 2.

Table 2. Lane changing Z-Test: Double sample average difference test.

\begin{tabular}{|c|c|c|}
\hline Parameter & Before Lane Changing $(\mathrm{km} / \mathrm{h})$ & After Lane Changing $(\mathrm{km} / \mathrm{h})$ \\
\hline Mean & 12.955 & 13.398 \\
\hline Known Covariance & 1.651 & 2.011 \\
\hline Observation Value & 100 & 100 \\
\hline Hypothetical Mean Difference & \\
\hline $\mathrm{z}$ & \multicolumn{2}{|c|}{-2.327} \\
\hline$P(Z \leq z)$ Single Tail & \multicolumn{2}{|c|}{0.00998} \\
\hline z Single Tail Critical & \multicolumn{2}{|c|}{1.645} \\
\hline $\mathrm{P}(\mathrm{Z} \leq \mathrm{z})$ Double Tail & \multicolumn{2}{|c|}{0.0199} \\
\hline z Double Tail Critical & \multicolumn{2}{|c|}{1.960} \\
\hline
\end{tabular}

(3) Generally, electric bicycles are slower than motor vehicles; in urban streets with large and mixed traffic volume, different arrival characteristics and headway of motor vehicular flow leads to different blocking effects to electric bicycles. A Z-test on the speed samples of electric bicycles from a normal situation and the performance under influence was carried out; the result indicates that when the motor vehicles accelerate and overtake the electric bicycle, for safety, the electric bicycle will slow down. The Z-test result is shown in Table 3.

Table 3. Effects of non-motor vehicles Z-Test: Two-sample mean difference test.

\begin{tabular}{|c|c|c|}
\hline Parameter & Normal Driving Speed $(\mathrm{km} / \mathrm{h})$ & Affected Speed $(\mathrm{km} / \mathrm{h})$ \\
\hline Mean & 13.306 & 12.400 \\
\hline Known Covariance & 1.226 & 1.8354 \\
\hline Observation Value & 100 & 100 \\
\hline Hypothetical Mean Difference & \multicolumn{2}{|c|}{0} \\
\hline $\mathrm{z}$ & \multicolumn{2}{|c|}{5.278} \\
\hline $\mathrm{P}(\mathrm{Z} \leq \mathrm{z})$ Single Tail & \multicolumn{2}{|c|}{$6.514 \times 10^{-8}$} \\
\hline z Single Tail Critical & \multirow{2}{*}{\multicolumn{2}{|c|}{$\begin{array}{c}1.645 \\
1303 \times 10^{-7}\end{array}$}} \\
\hline $\mathrm{P}(\mathrm{Z} \leq \mathrm{z})$ Double tail & & \\
\hline
\end{tabular}

Z-Test (two-sample mean difference test) was applied to test the speed difference between before and after changing lane in three conditions: "bicycle lane change to motorized lane", "motorized lane change to bicycle lane", and "electric bicycles under influence". The experiment indicated that the speed of electric bicycles can be improved by about $0.70 \mathrm{~km} / \mathrm{h}, 0.45 \mathrm{~km} / \mathrm{h}$, and $0.90 \mathrm{~km} / \mathrm{h}$ in the first, second, and third conditions, respectively.

From the above analysis, it is found that the motivation of electric bicycles changing from the bicycle lane to the motorized lane is to obtain higher speed. In order to quantify the utility value brought by the "illegal" lane-changing behavior, a Game Charge Matrix was constructed.

\section{Game Results and Analysis}

\subsection{Judgment Matrix}

In this part, the method of establishing a judgement matrix was used to calibrate the influence degree of electric bicycles on motor vehicles by lane-changing behavior. The approach of the establishment of a judgment matrix is as follows: each element with a downwardly membership relationship serves as the first (upper-left corner) element of the judgement matrix, and elements who are attached to this element are sequentially arranged in the first row and first column. Experts fill the 
matrix: according to the criterion of the judgement matrix, the elements are pairwise compared and judged as to which is more possible. The possibility was assigned as shown in Table 4 .

Table 4. Table of possible scale implications.

\begin{tabular}{cc}
\hline Megree of Importance Scale & Meaning \\
\hline 1 & Two elements are of the same probability \\
5 & The former is slightly probable than the latter. \\
7 & The former is obviously much probable than the latter \\
9 & The former is much more probable than the latter \\
$2,4,6,8$ & The former is significantly more probable than the latter \\
Countdown & The median value of the above judgment \\
If the ratio of element $i$ to element $j$ is a is $a_{i j}$, then the ratio of \\
element $j$ to the $i$ of the element is $a_{j i}=1 / a_{i j}$
\end{tabular}

$$
a_{i j}>0 ; a_{j i}=\frac{1}{a_{i j}} ; a_{i i}=1
$$

After being filled out, the judgment matrix $A=\left(a_{i j}\right)_{n \times n}$ has the above properties and is a symmetric matrix. The lane-changing behavior of electric bicycles was selected as the major factor by which bicycles influence motor vehicles to accelerate to stop the bicycle $f_{1}$, decelerate to yield $f_{2}$, or change lane $f_{3}$, as shown in Figure 2 .

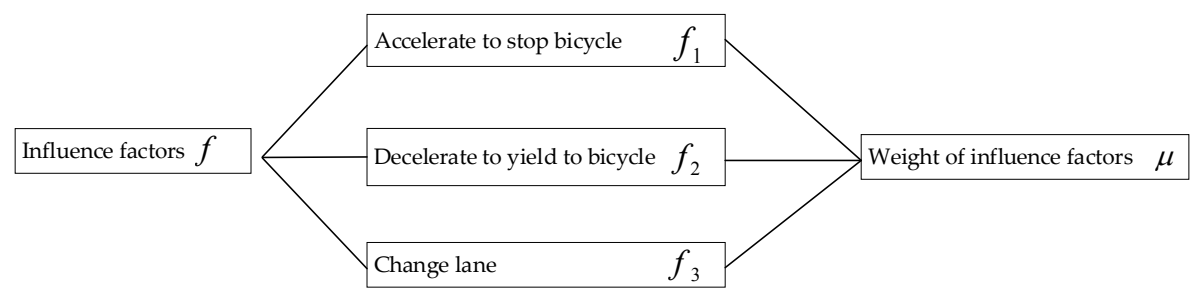

Figure 2. Hierarchical structure model of the influence factors.

It is necessary to employ some mathematical method to hierarchically sort the completed judgment matrix; in this part, a "normalization" approach was selected. The principle of this approach is that for a consistent matrix, the normalization of each column is the weight vector; for an inconsistent matrix, the normalization of each column is approximately the weight vector, and the arithmetic mean of the $n$ column vectors is taken as the final weights. The calculating formula is as following formula (4). The judgement matrix and the normalization for changing lane action is shown in Table 5 . The judgement matrix and normalization for remain in bicycle lane is shown in Table 6 .

$$
W_{i}=\frac{1}{n} \sum_{j=1}^{n} \frac{a_{i j}}{\sum_{k=1}^{n} a_{k l}}
$$

Table 5. Judgement matrix and normalization for changing lane action.

\begin{tabular}{cccccccc}
\hline & Judgment Matrix & \multicolumn{5}{c}{ Normalized Matrix } \\
\hline$f_{1}$ & $f_{2}$ & $f_{3}$ & $f_{4}$ & $f_{1}$ & $f_{2}$ & $f_{3}$ & $f_{4}$ \\
$f_{2}$ & 1 & 0.2 & 4 & $f_{2}$ & 0.242 & 0.048 & 0.969 \\
$f_{3}$ & 5 & 1 & 8 & $f_{3}$ & 0.527 & 0.105 & 0.843 \\
$f_{4}$ & 0.25 & 0.125 & 1 & $f_{4}$ & 0.241 & 0.120 & 0.963 \\
\hline
\end{tabular}

The weights of factors influencing the electric bicycles changing lane into the motorized lane are $(0.419667,0.491667$, $0.441333)$. 
Table 6. Judgement matrix and normalization for remain in bicycle lane.

\begin{tabular}{cccccccc}
\hline & Judgment Matrix & \multicolumn{5}{c}{ Normalized Matrix } \\
\hline$f_{1}$ & $f_{2}$ & $f_{3}$ & $f_{4}$ & $f_{1}$ & $f_{2}$ & $f_{3}$ & $f_{4}$ \\
$f_{2}$ & 1 & 8 & 5 & $f_{2}$ & 0.105 & 0.843 & 0.527 \\
$f_{3}$ & 0.125 & 1 & 0.25 & $f_{3}$ & 0.120 & 0.963 & 0.241 \\
$f_{4}$ & 0.2 & 4 & 1 & $f_{4}$ & 0.0485 & 0.969 & 0.242 \\
\hline
\end{tabular}

The weight of factors that influence the electric bicycles to remain in the bicycle lane without changing lane are $(0.491667,0.441333,0.419833)$.

\subsection{Payoff Analysis}

The lane-changing behavior of electric bicycles from the bicycle lane to the motored lane is a typical non-cooperative game. The electric bicycle is ridden based on the cyclist's own optimal benefit. The lane changing decision was made based on the observation and analysis of space of the motor lane and the speed of the vehicular traffic flow, and the cyclist will determine the payoff function based on the minimum space headway and clearance as well as the speed expectation. In this case, the payoff matrix is calculated as Table 7 .

Table 7. Payoff matrix.

\begin{tabular}{cccc}
\hline \multicolumn{4}{c}{ Payoff for All Policy Combinations } \\
\hline \multirow{2}{*}{$C_{1}$} & \multicolumn{3}{c}{$\boldsymbol{C}_{\mathbf{2}}$} \\
\cline { 2 - 4 } & Accelerating Stop $\boldsymbol{q}_{\mathbf{1}}$ & $\boldsymbol{q}_{\mathbf{2}}$ & $\mathbf{1}-\boldsymbol{q}_{\mathbf{1}}-\boldsymbol{q}_{\mathbf{2}}$ \\
\hline Lane changing $p$ & $\left(V_{f}, 0.419667\right)$ & $\left(V_{1}, 0.491667\right)$ & $\left(V_{2}, 0.441333\right)$ \\
No change $1-p$ & $\left(V_{3}, 0.491667\right)$ & $\left(V_{3}, 0.441333\right)$ & $\left(V_{3}, 0.419833\right)$ \\
\hline
\end{tabular}

Expected payoff of electric bicycles lane changing:

$$
u_{a}=p\left[V_{f} q_{1}+V_{2} q_{2}+V_{1}\left(1-q_{1}-q_{2}\right) \cdot\right]+(1-p)\left[V_{3} q_{1}+V_{3} q_{2}+V_{3}\left(1-q_{1}-q_{2}\right] .\right.
$$

Expected payoff of affected motor vehicles:

$$
\begin{gathered}
u_{b}=p\left[0.419667 q_{1}+0.491667 q_{2}+0.441333\left(1-q_{1}-q_{2}\right)\right] \\
+(1-p)\left[0.491667 q_{1}+0.441333 q_{2}+0.419833\left(1-q_{1}-q_{2}\right]\right. \\
V_{f}=\bar{V}+a_{k} t
\end{gathered}
$$

where $V_{1}$ is average speed difference before and after changing from the bicycle lane to the motored lane for the 100 electric bicycle samples; $V_{2}$ is the average speed difference before and after changing from the motored lane back to the bicycle lane of the 100 electric bicycle samples; and $V_{3}$ is the average speed difference of the electric bicycle before and after being influenced by motored vehicles. The average speed of electric bicycles on the study road section $\bar{V}$ is $13 \mathrm{~km} / \mathrm{h}$, the vehicle accelerating time $t$ is $3 \mathrm{~s}, a_{k}$ is the acceleration of the No. $k$ electric bicycle, in this case, the $a_{k}$ is $-2 \mathrm{~m} / \mathrm{s}^{2}$, and the average value of the $40 \%-60 \%$ percentile of the sample was selected as $p$.

$$
\begin{gathered}
\max U=\max _{a}+\max U_{b} \\
\left\{\begin{array}{l}
U_{a}=p\left[V_{f} q_{1}+V_{1} q_{2}+V_{2}\left(1-q_{1}-q_{2}\right)\right]+(1-p)\left[V_{3} q_{1}+V_{3} q_{2}+V_{3}\left(1-q_{1}-q_{2}\right)\right] \\
U_{b}=p\left[0.419667 q_{1}+0.491667 q_{2}+0.441333\left(1-q_{1}-q_{2}\right)\right] \\
+(1-p)\left[0.491667 q_{1}+0.441333 q_{2}+0.419833\left(1-q_{1}-q_{2}\right)\right]
\end{array}\right.
\end{gathered}
$$




$$
\begin{gathered}
\text { Constraint : }\left\{\begin{array}{l}
V_{1}=0.686 \mathrm{~km} / \mathrm{h} \\
V_{2}=0.443 \mathrm{~km} / \mathrm{h} \\
V_{3}=-0.906 \mathrm{~km} / \mathrm{h} \\
p=0.402272 \\
0 \prec q_{1} \prec 1 \\
0 \prec q_{2} \prec 1 \\
0 \prec q_{1}+q_{2} \leq 1
\end{array}\right. \\
\max U=\max U_{a}+\max U_{b} \\
U_{a}=2.6377 q_{1}+0.0981 q_{2}-0.3633
\end{gathered}
$$

The objective function is a multi-objective optimization problem; the solution shows that the minimum value of the $p$ is 0.304 , and the minimum expected payoff of the lane-changing electric bicycles $\mathrm{A}$ and the affected motor vehicle $\mathrm{B}$ is as follows:

$$
\begin{aligned}
q_{1} & =0.304, q_{2}=0.304 \\
\min U_{a} & =0.468, \min U_{b}=0.449
\end{aligned}
$$

That is, when the electric bicycles change lane, no matter what strategy the motor vehicle takes, its payoff is less than the expected payoff of the electric bicycles, in other words, the electric bicycle will achieve higher payoff through a lane-changing action. When all the electric bicycles in the system are ridden based on the optimal benefit of the cyclists, the system will reach the "Nash equilibrium".

\subsection{Modeling the Confliction between Electric Bicycles and Vehicles}

According to a field survey, electric bicycles change lane frequently in order to obtain higher speed, even snaking. The heavy body of the electric bicycles and random swing characteristics greatly threaten vehicular traffic and traffic safety. Through the analysis of the expected payoff function, it is certain that "illegal" lane-changing action will bring speed improvement for the electric bicycles, but it also causes the electric bicycles to grab the road resources of motor vehicles, leading to traffic confliction between bicycles and vehicles.

As show in the analysis above, the purpose of the lane-changing action of electric bicycles is to overtake the bicycles ahead by acceleration, and achieve higher speed and better riding space. So, the confliction model was established as a lane-changing-overtaking-confliction process, as shown in Figure 3.

Model assumptions:

(1) The speeds of the electric bicycles obey the normal distribution $\mathrm{N} N\left(\mu_{i}, \sigma_{i}\right)$.

(2) In the electric bicycle overtaking process, the overtaker completes the mission with initial velocity $v_{k}$ and acceleration $a_{k}$.

(3) For multilane sections, the electric bicycle entering the adjacent motor lane is counted as a conflicting event; multiple changes between motor lanes are not repeatedly counted.

(4) The condition of the lane-changing overtaking is that the slow electric bicycle gets into the road section ahead of the overtakers and gets out later than the overtakers. 


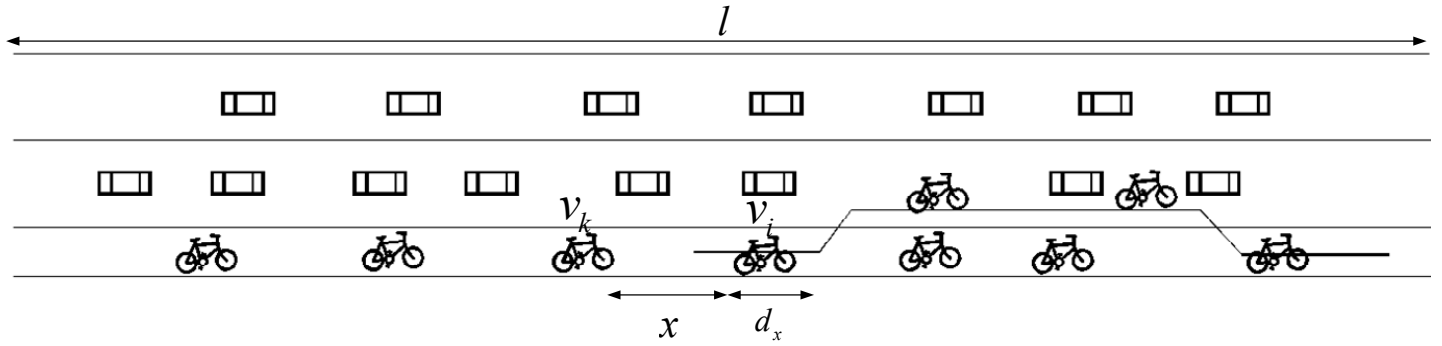

Figure 3. Lane-changing confliction between electric bicycle and vehicles of the same direction.

For a given transportation mode, the probability that the vehicle with average speed $v_{k}$ and acceleration $a_{k}$ overtakes the slower one $i$ ahead is:

$$
p\left(v_{i}\right)=p\left(\frac{(l-x)}{v_{i}} \succ \frac{l}{v_{k}}\right)=p\left(v_{i} \prec v_{k}\left(1-\frac{x}{l}\right)\right)
$$

where $p\left(v_{i}\right)$ is the probability of the vehicle ahead being overtaken by the subject, $v_{i}$ is the average speed $(\mathrm{km} / \mathrm{h})$ of the electric bicycle $i$ ahead of the subject, $l$ is the length of the survey road section $(\mathrm{km})$, and $x$ is the initial distance between the two electric bicycles $(\mathrm{km})$.

According to the assumptions, the speeds of lane-changing electric bicycles obey the normal distribution. The road section $l$ is divided into $x$ segments, and the length of each segment $d x$ assumes that the cumulative transcendental probability is $F(x)$; then, the transcendental probability in each fragment can be expressed as the average of the starting point and the terminal transcendental probability.

$$
p\left(v_{i}\right)=0.5[F(x-d x)+F(x)]
$$

According to Pacey's research [20], the normal distribution function was employed to describe the distributional characteristics of the speed of electric bicycles. It is assumed that the electric bicycle keeps a constant speed after crossing the stop line at an intersection, but the speeds of the electric bicycles are different from each other in the traffic flow, and each speed obeys the deformed normal distributions:

$$
q_{d}(j)=\sum_{i=1}^{j} q_{o}(i) g(j-i)
$$

where $q_{d}(j)$ is the arrival rate of the downstream flow during period $j(v e h / h) ; q_{o}(i)$ is the upstream flow rate at the stop line during period $i(v e h / h)$; and $g(j-i)$ is the probability distribution function of electric bicycle with a travel time $(j-i)$ from the upstream stop line section to the downstream stop line section.

Further,

$$
g(T)=\frac{\alpha}{T^{2} S \sqrt{2 \pi}} e^{\left(\frac{-(\alpha / T-\bar{V})^{2}}{2 S^{2}}\right)}
$$

where $T$ is the travel time of the electric bicycle; $\alpha$ is the distance between some section downstream and the stop line upstream; $\bar{V}$ is the average speed of the traffic flow; and $S$ is the standard deviation of the speed of the electric bicycles.

The travel time from cross section $j$ to $i$ is $t$, and $t$ obeys a normal distribution; then,

$$
q_{d}(j)=\sum_{i=1}^{j} q_{o}(i) \frac{\alpha}{T^{2} S \sqrt{2 \pi}} e^{\left(\frac{-(\alpha / T-\bar{V})^{2}}{2 S^{2}}\right)}
$$


The relationship between the frequency of bicycle lane changing and the flow rate of the traffic was obtained through field survey. The expected conflicting time of electric bicycle $k$ overtaking electric bicycle $i$ during each time interval is

$$
\begin{gathered}
E\left(p_{\frac{k}{i}}\right)=\sum_{j=1}^{n} p\left(v_{i}\right) \times q_{\frac{k}{i}} \times d x_{j} \\
q_{\frac{k}{i}}=0.378 q_{d}(j)-0.24916
\end{gathered}
$$

$E\left(p_{\frac{k}{i}}\right)$ is the number of expected events above in the unit time interval, $q_{\frac{k}{i}}$ is the predicted arrival rate of the electric bicycle (veh $/ h)$, and $d x_{j}$ is the division of the length of each segment; according to the situation in China and previous research, in this paper, $d x_{j} \in(10,15)$. That is, the sum of expected events in a unit interval (minutes) is

$$
E\left(p_{k}\right)=\sum_{i} E\left(p_{\frac{k}{i}}\right)
$$

According to the analysis above, a lane-changing-overtaking-confliction model was established and the conflicting event number during the unit time interval was determined. However, the impact of confliction on traffic safety was not quantified effectively. Therefore, in the following parts, safety analysis based on conflicting events for the lane-changing behavior will be studied further.

\subsection{Safety Level Analysis}

The Level of Service (LoS) of bicycle lanes in HCM2010 is described by the concept of interference events. Table 8 lists the LoS division of the HCM2010 for bicycle lanes. In accordance with the LoS of motor vehicles, the LoS of bicycles is divided into 6 grades, A-F.

Table 8. Level of Service of bicycle lane [21].

\begin{tabular}{cc}
\hline Level of Service & Number of Interference Events (times/hour) \\
\hline A & $\leqq 40$ \\
B & $>40-60$ \\
C & $>60-100$ \\
D & $\geqq 100-150$ \\
E & $>150-195$ \\
F & $\geqq 195$ \\
\hline
\end{tabular}

Note: Width of bicycle lane is $2.0 \mathrm{~m}$.

Referring to the cycling LoS given in HCM2010, the safety level of a bicycle lane is proposed. The safety level of electric bicycles can be divided into four levels, listed as I-Very safe, II-Safe, III-Unsafe, and IV-Danger. Through the survey of the mixed-flow sections of Zhangbadong road, Yanta interchange, Chang' an interchange, and Nanerhuan road in $\mathrm{Xi}^{\prime}$ an, arrival rates and lane-changing event samples of electric bicycles in 200 time intervals ( $1 \mathrm{~min}$ for each interval) were documented; Origin software was employed to analyze the samples and the graph shown in Figure 4 was generated.

According to the conflict threshold of the electric bicycle in the unit time interval determined by the graph, considering the urban road conditions and the running characteristics of electric bicycles, the traffic conflict coefficient and the safety level threshold are shown in Table 9.

Table 9. Safety level.

\begin{tabular}{ccc}
\hline Grade & Security Level & Number of Lane-Changing Events/Arrival Rate (Vehicle/min) \\
\hline Very Safe & I & $<0.2687$ \\
Safe & II & $(0.2687,0.4031)$ \\
Not Safe & III & $(0.4031,0.6719)$ \\
Dangerous & IV & $>0.6719$ \\
\hline
\end{tabular}




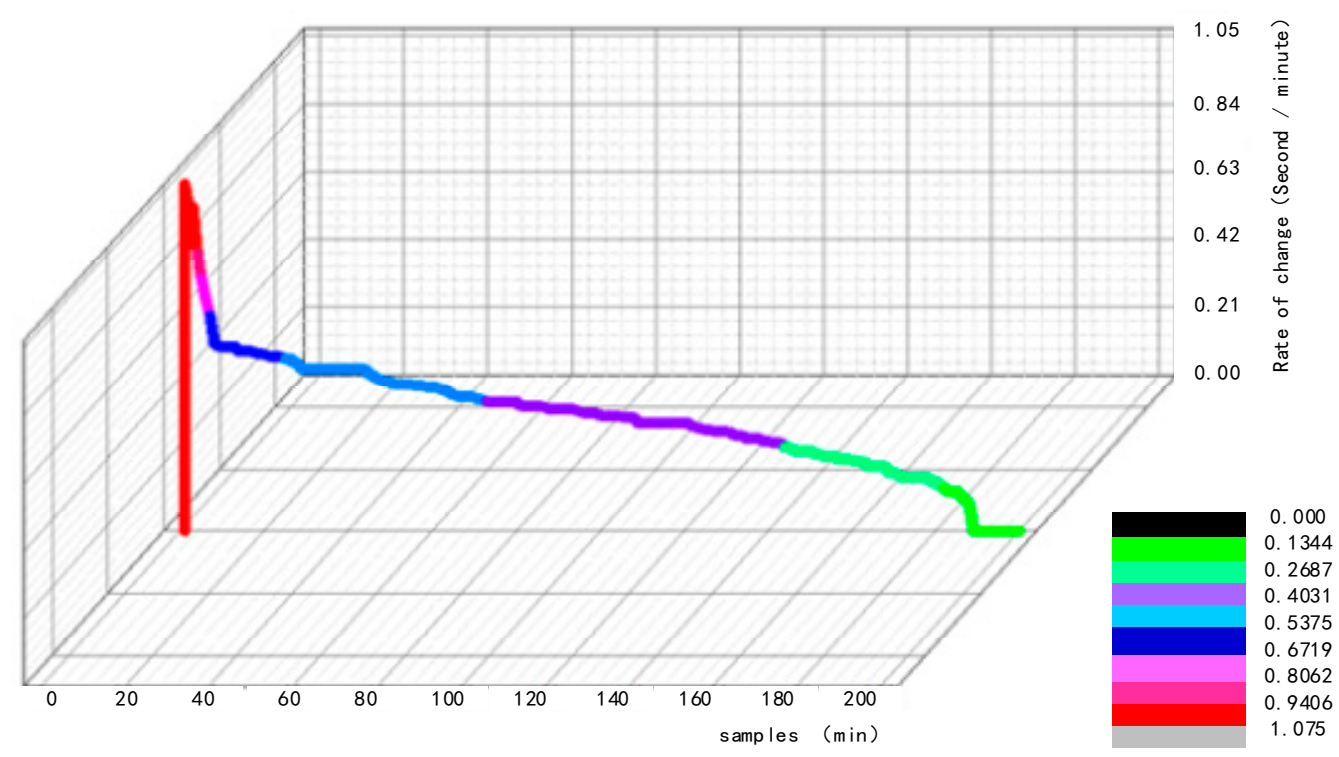

Figure 4. Conflict rate of unit time interval.

\section{Conclusions and Future Study}

In this paper, the "illegal" lane-changing behavior of electric bicycles was studied by means of a strategy game based on non-cooperation with complete information, and the Z-test (double sample mean difference test) was employed to analyze the collected data; a payoff matrix and a lane-changing confliction model were established and the benefit of speeding as well as the threat of accidents due to lane changing was also studied. We draw the following conclusions.

(1) The "illegal" lane-changing behavior of electric bicycles is desired-speed-oriented; the cyclists obtain more riding space and increase the comfort of riding by changing lanes.

(2) In road sections with large traffic volume, when the motor vehicle in the adjacent lane is faster, the electric bicycle tends to decelerate and increase lateral clearance to ensure safety.

(3) Electric bicycles have become an important accident hazard in urban traffic systems due to their high flexibility in direction control and speed control, as well as the arbitrary lane-changing and overtaking behavior.

(4) The "illegal" behavior of electric bicycles is more prominent in road sections with large traffic volume, when the safety grading reaches above III; corresponding measures should be taken to separate the motor vehicle and electric vehicle flow, such as greening facilities, guardrails, raising non-motor vehicle lanes, etc.

According to the survey in $\mathrm{Xi}^{\prime}$ an, the recommended value of the safety critical threshold of the electric bicycle lane changing is obtained from a statistical point of view, which is of great reference significance for urban electric bicycle management; in the future, electric bicycles can be further explored through the following aspects.

(1) According to different urban road types and hierarchies, the operating characteristics of electric bicycles under different vehicle arrival characteristics as well as the hazard levels under different conditions should be studied further, allowing the formulation of more scientific and reasonable implementation policies for e-bike management. The result would be references for the implementation of rational policies for electric bicycle management.

(2) The impact of road separation devices on the traffic confliction should be studied to a further extent; the result would be an important reference for the design and operation of mixed-traffic facilities. 
Author Contributions: Conceptualization by H.S. and J.W.; Methodology by H.S. and J.W.; Software by J.W.; Investigation by Y.W. and S.C.; Writing-Original Draft by J.W.; Writing-Review \& Editing by H.S. and J.W.; Supervision, H.S.

Funding: This research was supported by the Fundamental Research Funds for the Central Universities: 300102218409: Data-driven traffic design and cooperative control for intersection group; Technical innovation Funding of China Academy of Urban Planning \& Design (Grant No. C-201728): Traffic congestion mechanism analysis based on data mining technology.

Acknowledgments: In the process of writing this paper, Zheng, for valuable suggestions on the discussion of the preliminary ideas of the paper, and the help in the investigation of the road sections and data processing; $\mathrm{Li}$ provided plug-in support for data processing. In particular, my roommate gave me a lot of encouragement in the process of paper writing.

Conflicts of Interest: The authors declare no conflict of interest.

\section{References}

1. Kuang, X.Y.; Wu, Y.; Cao, W.H.; Wu, Y.F. Cellular automata simulation model for urban mixed non-motor vehicle flow. J. Guangxi Norm. Univ. 2015, 33, 7-14. (In Chinese)

2. Guan, H.Z.; Wang, W.M.; Chi, H.B. Study on road traffic delay caused by bicycle for mixed traffic system. J. Beijing Univ. Technol. 2005, 3, 281-283. (In Chinese)

3. Liu, Y.; Cheng, R.J.; Lei, L.; Ge, H.X. The influence of the non-motor vehicle for the car-following model considering traffic jerk. Phys. A 2016, 463, 376-382. [CrossRef]

4. Bagloee, S.A.; Sarvi, M.; Wallace, M. Bicycle lane priority: Promoting bicycle as a green mode even in congested urban area. Transp. Res. Part A 2016, 87, 102-121. [CrossRef]

5. Zhang, Y.L. Discretionary lane changing modeling based on stackelberg Game Theory. J. Transp. Syst. Eng. Inf. Technol. 2014, 14, 67-73. (In Chinese)

6. Liu, X.M.; Zheng, S.H.; Jiang, X.C. Lane changing model based on discrete dynamic game. J. Highw. Transp. Res. Dev. 2008, 6, 120-125. (In Chinese)

7. Xue, C.M.; Tan, G.Z.; Ding, N.; Liu, M.J.; Du, W.Q. Cooperative lane-changing model of human driving and unmanned driving based on Game Theory. Comput. Eng. 2017, 43, 261-266. (In Chinese)

8. Talebpour, A.; Mahmassani, H.S.; Hamdar, S.H. Modeling lane-changing behavior in a connected environment: A game theory approach. Transp. Res. Procedia 2015, 7, 420-440. [CrossRef]

9. Wang, M.; Hoogendoorn, S.P.; Daamen, W.; van Arem, B.; Happee, R. Game theoretic approach for predictive lane-changing and car-following control. Transp. Res. Part C Emerg. Technol. 2015, 58, 73-92. [CrossRef]

10. Hu, L.W.; Li, L.; Wang, M.; Yu, T.Y. Rules of vehicular operation based on the gaming behavior of drivers during growth of traffic congestion. Chin. J. Ergon. 2017, 23, 62-66, 71. (In Chinese)

11. Yang, X.F.; Zhang, S.; Fu, Q. Research of driving behavior under condition of complete information based on Game Theory. J. Highw. Transp. Res. Dev. 2015, 32, 105-111. (In Chinese)

12. Zhang, L.; Huang, X.W.; Wu, W.M. Mixed driving behavior game analysis. J. Highw. Transp. Res. Dev. 2014, 31, 116-123. (In Chinese) [CrossRef]

13. Tang, T.Q.; Luo, X.F.; Zhang, J.; Chen, L. Modeling electric bicycle's lane-changing and retrograde behaviors. Phys. A 2018, 490, 1377-1386. [CrossRef]

14. Miao, M.Y.; Shang, H.Y.; Pei, J.R. On the classification of the hazardous behaviors of the non-motor vehicle drivers. J. Saf. Environ. 2014, 14, 106-111. (In Chinese)

15. Zhang, S.C.; He, K.K.; Dong, S. Test scale design for traffic behavior safety evaluation of non-motorized vehicle rider. China Saf. Sci. J. 2015, 25, 111-117. (In Chinese)

16. Wang, X.M.; Jiang, H.P.; Wu, W.Y. Traffic safety of non-motorized vehicle based on traffic conflict technique. J. Highw. Transp. Res. Dev. 2011, 28, 110-114. (In Chinese)

17. Petzoldt, T.; Schleinitz, K.; Heilmann, S.; Gehlert, T. Traffic conflicts and their contextual factors when riding conventional vs electric bicycles. Transp. Res. Part F 2017, 46, 477-490. [CrossRef]

18. Lin, X.; Wells, P.; Sovacool, B.K. The death of a transport regime? The future of electric bicycles and transportation pathways for sustainable mobility in China. Technol. Forecast. Soc. Chang. 2018, 132, 255-267. [CrossRef] 
19. Baptista, P.; Pina, A.; Duarte, G.; Rolim, C.; Pereira, G.; Silva, C.; Farias, T. From on-road trial evaluation of electric and conventional bicycles to comparison with other urban transport modes: Case study in the city of Lisbon, Portugal. Energy Convers. Manag. 2015, 92, 10-18. [CrossRef]

20. Pacey, G.M. The Progress of a Bunch of Vehicles Released from a Traffic Signal; Road Research Laboratory: London, UK, 1956.

21. Transportation Research Board. Highway Capacity Manual; TRB, National Research Council: Washington, DC, USA, 2010.

(c) 9

(C) 2018 by the authors. Licensee MDPI, Basel, Switzerland. This article is an open access article distributed under the terms and conditions of the Creative Commons Attribution (CC BY) license (http:/ / creativecommons.org/licenses/by/4.0/). 